\title{
Actual and Self-perceived Spelling Accuracy in Kuwaiti EFL Students: Some Practical and Theoretical Implications
}

Madeline Haggan

A spelling elicitation test on common English spelling errors already collected from native Arabic-speaking students was devised and administered to 25 Remedial and 25 Fourth Year students from the English Department of Kuwait University. In addition to providing the targetted words, students were also required to score each response as follows: 4 if they were sure they had spelled the word correctly, 3 if they felt it was probably correct, 2 if they felt it was probably wrong, and 1 if they felt it was definitely wrong. Results showed that there was no significant difference between the two groups on the self-ratings, with both showing a high level of confidence over the accuracy of their spelling whether they were spelling words correctly or incorrectly. Since, in general, both groups' actual spelling accuracy was far lower than their self-perceived spelling accuracy, this points to a situation in which students do not know that they do not know. A personality test administered to the students showed a strong bias towards extra-version and a correlation was found between scores on spelling confidence and degree of extraversion. The findings are discussed from the point of view of their implications for (a) methods of collecting spelling errors for analytical study and (b) the Monitor model.

\section{INTRODUCTION}

The study of spelling errors is one which enjoys a long tradition in educational research, with Cahen, Graun and Johnson (1971), in their review of the published literature, citing papers published as early as 1914. However, far from being an exhausted field, it is still generating research interest and a particular thrust has been in the direction of spelling errors perpetrated by EFL students. Perhaps rather surprisingly, though, there has been comparatively little work done in this area (see Bebout, 1985, for a review of relevant studies). This may be because, in spite of offering what would appear to be a fairly contained area for research, the study of spelling errors, whether in native or non-native English, is not as straightforward as it might appear. One area of potential pitfall is in the method used to gain access to an individual's spelling competence. At first glance, one might say: just use a spelling test. However, this presupposes a basis for the selection of words to 
be tested which, in turn, implies a hypothesis about why these words would be difficult. In EFL, the contrastive analysis of native and target languages as an indicator of possible difficulty is too well-known to need explanation, but a study by Oller and Ziahosseiny (1970) on spelling shows that performance predictions based on contrast are not always in the expected direction. They found, for instance, that EFL students whose native language used the same Roman script as English made more spelling errors than those whose native language uses a non-Roman script. A further methodological problem arises from the fact that spelling tests are usually given orally so that the tester's pronunciation of the target words becomes a factor affecting subjects' responses. The traditional alternative to the spelling test approach is to collect errors as they occur spontaneously in samples of written work. As early as 1932 it was pointed out by Fitzgerald, however, that such data may also suffer some bias since subjects may avoid trying to use words of whose spelling they are unsure. The phenomenon of avoidance (of difficulty) in the linguistic production of EFL students is one which has attracted some interest in more recent times. For example, syntactic avoidance has been documented by Schachter (1974), Swain (1975) and Kleinmann (1977; 1978), morphological avoidance by Perkins and Larsen-Freeman (1975), and semantic avoidance by Tarone, Frauenfelder and Selinker (1975) and Ickenroth (1975). It would not, therefore, seem beyond the limit of reasonable expectation that spelling avoidance may also be a reality. Certainly on the basis of Fizgerald's hypothesis (1932), Bebout (1985) eschewed the collection of spelling errors as they occur in free writing and devised an elicitation approach whereby written sentence frames with a missing word were presented to subjects who had to write down the word they felt was most appropriate in the given context. This, she felt, imposed a degree of constraint on the subject who could not, in theory, avoid the words he found difficult to spell. However, this idea of spelling avoidance itself rests on another assumption, namely that the individual has some insight into his own level of accuracy and is actually aware of which words he knows how to spell correctly and which words he is misspelling. Superficially, there may be some intuitive validity to this idea since even highly educated native speakers have recourse to the dictionary on occasion to check the spelling of a word. However, even if we assume that native speakers have this degree of insight into their own spelling prowess, it may not be realistic to make the same assumption about EFL students. To reject spontaneous writing samples as a source of EFL spelling errors on the basis of presumed 
avoidance tactics may therefore be too dismissive. It seemed worthwhile to clarify this area of speculation and ascertain on more solid grounds how far EFL students are aware of their own spelling accuracy or inaccuracy since only then could the spelling avoidance thesis be supported or rejected. Accordingly, the following experiment was carried out.

\title{
METHOD
}

\section{Subjects}

Fifty subjects took part in the experiment, all of whom were undergraduates majoring in English at the English Department, University of Kuwait. Twenty-five of the subjects were First Year students taking a non-credit Remedial course, having been assigned to this class on the basis of their low scores on the Departmental Placement Test. The other twenty-five were Fourth year students in their graduation year. All subjects were native speakers of Arabic.

\section{Materials}

Thirty words were selected from those commonly misspelled in a survey previously conducted on the spelling performance of Remedial and Fourth Year students in the above-mentioned English Department (Haggan, 1991). These had been collected from the final examination scripts of two writing courses, one at the Remedial level and one at the Fourth Year level. Of the words selected for the present study, roughly half were taken from the Fourth Year papers and half from the Remedial papers, but all were high-frequency words which would have been within the lexical capacity even of the Remedial students. Sentence frames were then built up around these words, designed to elicit the word in question.

\author{
Example target word: swimming \\ sentence frame: In summer it is pleasant to stay \\ in the .......pool.
}

As much care as possible was taken to ensure that the context would elicit the desired word. Where several possible alternatives could fit into the blank, additional cues were given by supplying the first, and sometimes also the last, letters of the targetted word. As a further check, the test was given to two native speakers of English. (The complete test is presented in Appendix B). 


\section{Procedure}

Copies of the elicitation test were distributed to subjects in class along with copies of a specially-prepared instructions sheet (Appendix A). Briefly, subjects were required to write a word to fit in the blank space in each sentence. In addition, they were asked to assess their feelings about their accuracy in spelling each word by writing 4 if they were sure they had spelled the word correctly, 3 if they felt it was probably correct, 2 if they felt it was probably wrong and 1 if they felt it was definitely wrong. Papers were then collected and each was marked to obtain the total number of correct spellings for each student to get a score for accuracy. By totalling the self-assigned marks out of four for each word, a confidence score was also obtained for each student.

\section{Results}

In spite of all efforts to reduce variation in elicited responses, 227 out of the total 1500 responses obtained were different from the target words (114 of these variant responses were from Remedial students, and 113 were from Fourth Year students). It did not appear that this was an active attempt on the part of subjects to avoid these words for the sake of more-easily spelled alternatives because many of them were more difficult than the target word e.g., where terrible was given instead of tired, semester instead of final, previous instead of entire, and roughly instead of really. In a few cases, the response given was a viable but unanticipated alternative to the target word, but largely this tendency arose out of failure on the part of subjects to guess what the "right" word was, and says more about their knowledge of vocabulary and sensitivity to context cues than about spelling.

Turning to spelling, the first, rather striking, point that emerged was that, out of the 1500 responses, only 338 (or 22.5\%) were misspellings. This is surprisingly low in view of the fact that the target words were those commonly misspelled in the writing samples from which they had been drawn. Two possible explanations could account for this:

a) The student populations were different. The writing samples were, in fact, produced by different students from those doing the elicitation task. However, there are no reasons (i.e. based on general academic performance) to suspect that the student populations differed as regards their competence in English. 
b) The different test conditions were responsible. Students may make more spelling errors in spontaneous essay writing, especially under examination conditions, than in special tests where they know attention is focussed on spelling.

The second point was that the relative number of errors made by Fourth Year and Remedial students showed a substantial difference. The more advanced group made 138 errors, while the Remedial group made 200 errors. This translates into a ratio of $41: 59 \%$ of all errors and simply indicates that students do, in fact, show a general improvement in spelling with increased exposure to the language. However, when we turn to students' perception of their accuracy, this difference between the two groups disappears.

TABLE 1

Confidence Ratings for Correctly Spelled Words

\begin{tabular}{crrrr}
\hline & \multicolumn{2}{c}{ Remedial } & \multicolumn{2}{c}{ Fourth Year } \\
Score & Freq. & $\%$ & Freq. & $\%$ \\
4 & 450 & 83.5 & 534 & 87.4 \\
3 & 75 & 13.9 & 58 & 9.5 \\
2 & 14 & 2.6 & 19 & 3.1 \\
1 & 0 & 0 & 0 & 0 \\
\cline { 2 - 5 } & 539 & 100 & 612 & 100 \\
\hline
\end{tabular}

TABLE 2

Confidence Ratings for Misspelled Words

\begin{tabular}{crrrr}
\hline & \multicolumn{2}{c}{ Remedial } & \multicolumn{2}{c}{ Fourth Year } \\
Score & Freq. & $\%$ & Freq. & $\%$ \\
4 & 87 & 43.5 & 73 & 53.9 \\
3 & 87 & 43.5 & 53 & 38.5 \\
2 & 23 & 11.5 & 11 & 7.9 \\
1 & 3 & 1.5 & 1 & 0.7 \\
\cline { 2 - 5 } & 200 & 100 & 138 & 100 \\
\hline
\end{tabular}

Tables 1 and 2 show frequencies for the four self-rating scores for correctly spelled words and misspellings respectively. Chi-square 
tests applied to the data did not reach significance in either case, thus not allowing rejection of the null hypothesis of no difference between the two groups. It may, therefore, be concluded that both groups were equally confident about the accuracy of their spelling, whether they were spelling words correctly or incorrectly. This can be seen more clearly in Table 3 which shows the percentages of correctly and incorrectly spelled responses rated as 3 or 4 .

TABLE 3

Percentages of Responses Rated as 3 or 4

\begin{tabular}{lcc}
\hline & Correctly spelled & Misspelled \\
Remedial & 97.4 & 87.0 \\
Fourth Year & 96.9 & 91.4 \\
\hline
\end{tabular}

In view of the high percentages obtained for both groups, a situation is revealed in which the confidence in spelling accuracy shown by the students taking part in this study far outstrips their actual accuracy, with this phenomenon not being significantly affected by level of competence in English. This may be further shown by working out the percentage mean confidence scores and percentage mean accuracy scores ${ }^{1}$ for the two groups and comparing them. This data is shown in Table 4 and it can be seen that for both groups, the accuracy score is considerably less than the confidence score. In addition, while the difference between Remedial and Fourth Year students on their confidence score is only 3.3 , the difference between them on accuracy is three times as great (9.3).

TABLE 4

Confidence vs. Accuracy

\begin{tabular}{lccc}
\hline & Remedial & Fourth Year & Difference \\
\% Mean Confidence Score & 90.9 & 94.2 & 3.3 \\
\% Mean Accuracy Score & $\underline{\mathbf{7 3 . 5}}$ & $\underline{81.6}$ & 9.3 \\
Difference & 17.6 & 12.6 & \\
\hline
\end{tabular}




\section{Discussion}

The subjects in our study showed themselves to be very confident about their spelling accuracy, a tendency that is particularly striking when, in fact, they are spelling words wrongly. The figures obtained point to an overwhelming lack of awareness on the part of these students that they did not know how to spell the words in question and, therefore, lead to a re-appraisal of the concept of avoidance in linguistic production. Kleinmann (1977) has made the point that "...an individual cannot be said to be avoiding a given syntactic structure, morpheme or lexical item, which he does not have in his linguistic repertoire.... To be able to avoid some linguistic feature presupposes being able to choose not to avoid it, i.e., to use it" (p. 96). Our findings suggest that a corollary must be added to this. It may not be enough to say that the absence of a particular structure does not indicate avoidance if that structure is unknown to the subject. We must also say that the presence of an incorrectly expressed form or structure does not signify that the individual has chosen not to avoid it. The choice of whether or not to avoid rests not only on whether or not the individual has the particular item in his linguistic repertoire but also on whether or not he has a sufficiently high level of self-monitoring skill to judge his level of mastery of the item in question. If this degree of insight is absent, the individual may simply assume that what he produces is correct so that the need for avoidance does not arise. This would seem to have been the case with the subjects in our study: they simply did not know that they did not know. Therefore, avoidance tactics did not come into play at all.

In the Introduction, reference was made to the presupposition by Fitzgerald (1932) and Bebout (1985) that writers avoid words they do not know how to spell and that, therefore, collecting errors from free writing samples will not yield a true picture of an individual's level of spelling accuracy. The findings obtained show this presupposition to be erroneous, at least for the students taking part in this study. In addition, even a fairly restricting elicitation test as was used here did not result in eliminating non-target responses, many of which were as difficult or more difficult than the words targetted. This would seem to erode whatever advantage may derive from the use of specially-constructed elicitation tests as a controlled method of collecting spelling errors and would suggest that collecting errors from free writing samples may be as effective-and certainly simpler than-conducting special elicitation tests. Another point to be noted is the low number of errors that were collected 
from our elicitation test which had been constructed on the basis of common errors committed by similar students in examination compositions. The effect of different test conditions on spelling accuracy was not a focus of the present study, but it is one which would seem worth further investigation.

However, the most interesting question posed by the findings is surely why these students were so confident they were right when they were wrong. As a first step in answering this question, it may be useful to compare the performance of the students in our study with that of participants in two other studies who were asked to give self-ratings on the accuracy of their responses to see whether similar patterns emerge or whether our subjects were special or different. At the outset, however, it must be pointed out that such between-studies comparisons are limited because of differences in the area and type of material tested. Thus, Yule, Yanz and Tsuda (1985) had Japanese learners rate the accuracy of their own responses to a listening test. The binary nature of the response decision involved (i.e. a choice between the two words in a minimal pair) allowed the utilization of measuring procedures for monitoring performance borrowed from Signal Detection Theory which were rather different from the analysis used here. Additionally, the focus of their analysis was on individual differences rather than on group tendencies. Notwithstanding these differences of approach, it is interesting to note that they did uncover a pattern of "very confident wrong answering", although it is difficult from their data to derive how significant this was for the whole group so that direct comparison with our study is not possible. They also found a pattern of non-confident correct answering which was almost non-existent amongst our subjects. In a subsequent study, Yule, Damico and Hoffman (1987) applied the same analytical procedure in a test-retest situation conducted on a listening task over a seven week period during which time students participated in a pronunciation/ listening course. They found that one group's accuracy scores improved but their self-monitoring skill did not. This seems to be in agreement with our findings that Remedial and Fourth Year students did not differ significantly in their confidence scores. It is of interest to note, therefore, that the subjects in Yule et al's experiment (1987) came from a wide range of languagespeaking groups, arguing perhaps for some kind of generalized tendency to reach a plateau on this particular measure. On the other hand, it must also be underlined that the period separating test and re-test sessions in the study of Yule and his associates was only seven weeks, whereas the period separating the Remedial 
students and Fourth Year students in our study was, on average 4-4.5 years. It would surely be justifiable to expect the development of greater personal sensitivity to one's own English spelling performance over such an extended period of study within an English Department. In summing up, these studies do indicate that other groups show some of the confidence characteristics found in the students in our experiment but that there may be grounds for concluding that these characteristics are more pronounced in our subjects (i.e., there were very few cases of non-confident correct answering) and that they seem to be very resistant over time despite extensive language tuition. It may, therefore, be reasonable to assume that the high confidence scores shown by our subjects may be a feature characterizing the particular group this sample represents and to try to answer the question of why they were so confident on this basis. For example, since they were all native speakers of Arabic, an argument could be developed that they approached the process of English spelling with a set of inappropriate assumptions. Spelling in Arabic is regular in the sense that the spelling of a word, except in a handful of well-known cases (see Kharma \& Hajjaj, 1989, p. 56), is always predictable from its pronunciation. Spelling in English on the other hand, is most certainly not. It is true that certain patterns or families of similarities do exist, but membership cannot always be predicted and there are many exceptions. Arabic speakers could, therefore, be theorized as approaching English spelling with the expectation that it is regular. Thus, just as they would normally assume, with justification, that their Arabic spelling would always be accurate, so also, by extension, would they assume their English spelling to be accurate. Spelling, in other words, is not an area of linguistic concern to them. However, appealing as this theory may be, it cannot really explain the facts. Our subjects were university students and even those at the Remedial level must have been long acquainted with the reality of the irregularity of English spelling since all had studied English for about six years at school.

Perhaps a more fruitful line of thinking may arise from consideration of Krashen's construct of the monitor $(1975 ; 1977)$ which, as part of the learner's internal system concerned with conscious language processing, may perform an editing function on his or her linguistic output. Since "the more self-confident and the less self-conscious a learner is, the less reliance he or she places on the monitor" (Dulay, Burt \& Krashen, 1982, p. 77), the high confidence shown by the students in our study that their incorrect responses were correct could mark them as monitor under-users. In other 
words, they may have a store of "learned" knowledge about spelling rules and patterns (which would surely not be unexpected at university level) but they do not make maximum use of this knowledge to edit their output. At the intuitive level, this does not conflict with the writer's personal assessment of these students based on experience of over twenty years teaching EFL to Arab students, nor with the views of other, equally experienced, colleagues expressed in countless professional conversations. However, it is wise to bear in mind that our findings rest on the performance of a group of Kuwaiti EFL students and that care must be taken not to build too much on what are, after all, limited results. Indeed, extensive research is needed involving larger and more diverse samples of students to establish the concept of the monitor and its relationship to the learner's confidence on a more empirical basis.

From our own findings, however, it may be possible to add a footnote which might be a first step towards this. Krashen (1978) has further described monitor under-users as having an "outgoing, uninhibited personality...in contrast to the self-conscious, introverted personality of the over-user", but, as is so typical in his insights, he arrives at this perceived correlation between personality factors and monitor use through anecdotal evidence gathered from a few case studies, and not from formal personality testing of large samples of students nor from any objective measure of monitor use. Assuming the confidence scores obtained here provide such a measure of the latter, it seems a logical step to apply a more stringent test to his idea by investigating the relationship between these scores and scores on extraversion as obtained from a recognized personality test, thus testing the hypothesis that there would be a correlation between the two. Accordingly, an Arabic version of the Eysenck Personality Questionnaire (EPQ) $(1975)^{2}$ was administered to the same group of Fourth Year students who had already participated in the spelling test. Although final examination schedules meant that the Remedial group was no longer available for testing, it was felt that this was not necessarily a drawback since it could be argued that the high confidence scores shown by the Fourth Year students for their misspellings may point to a more persistent under-use of the monitor. The test was administered in class without prior notice so that, because of student absences, 20 out of the original 25 subjects in this group were tested. The mean score for the whole group on the introversion-extraversion scale was 13.4 which is well above the cut-off point of 10 which marks the start of extraversion. 
No of cases with Extraversion scores

No of cases with Average (ambivert) scores

No of cases with Introversion scores

\begin{tabular}{cccc}
\multicolumn{3}{c}{ (a) } & \multicolumn{2}{c}{ (b) } \\
\multicolumn{2}{c}{$\%$} & \multicolumn{2}{c}{$\%$} \\
15 & 75 & 14 & 70 \\
3 & 15 & 6 & 30 \\
$\frac{2}{20}$ & $\frac{10}{100}$ & $\frac{0}{20}$ & $\frac{0}{100}$
\end{tabular}

Notes:

1) Figures in Column (a) are derived from the usual cut-off points of above 10 to show extraversion, and below 8 to show introversion. Figures in Column (b) are derived from the more stringent cut-off points of above 11 for extraversion and below 7 for introversion.

2) Mean score for whole group $=13.4$

Mode $=15$

Median $=13.5$

Standard Deviation $=3.83$

Table 5 gives further information on the distribution of scores and provides more support for concluding that the group as a whole fell within the extraversion range. The correlation coefficient was then calculated between subjects' individual introversion-extraversion scores on the EPQ and their individual scores for errors rated as 3 or 4. A significant level was obtained $\left(r_{\mathrm{s}}=0.392, p<.05\right.$, one tailed test) indicating that, within the group, degree of extraversion correlated with degree of confidence that wrong answers were right.

Two points emerge from this that have to be considered separately. The first is the fact that the group as a whole should show such a strong bias towards extraversion. This, in itself, is an intriguing finding about which it would be unwise to generalize (e.g. to other Arab groups) without the backing of more extensive investigation involving much larger samples of students. However, future researchers may care to ponder the fact that, in a deeplyconservative Muslim society such as exists in Kuwait, the study of English literature is regarded by many members of the community as inappropriate and running counter to Islamic principles. On this basis, students who join the English Department may, therefore, have already undergone a kind of unofficial selection process which could result in the exclusion of certain personality types.

The second point to be considered is the correlation within the group between scores on extraversion and confidence scores. This seems to provide some empirical support for Krashen's thesis that 
there is a connection between extraversion and monitor under-use. Although our study is based on one group of learners from one cultural group, it is still fair to say that its findings are in line with those of a small band of researchers (e.g. Naiman et al., 1978, and Busch, 1982) who have found that, in general, extraversion does not seem to be an indicator of successful language learners. This is contrary to the widely-held stereotype that extraversion and/or confidence is generally a positive factor in $\mathrm{L}_{2}$ acquisition (Dulay, Burt \& Krashen, 1982, p. 75). Indeed emphasis has even been directed in EFL teaching at methods which try "to create" extraversion in students (Brown, 1987, p. 110). Brown (ibid.) tries to shed some light on this apparent contradiction by suggesting that extraversion may be a factor only in the development of oral competence and not in the development of competence in listening, reading and writing. Our own findings are based on awareness of spelling accuracy, which would form a sub-skill contributing to writing competence. As such, they may go a small way to validating this suggestion. It seems timely now for both teachers and researchers to look more closely at what might be the facilitative and debilitative contributions of this aspect of the learner's personality.

To sum up, the findings of this paper are interpretable on two levels. The first of these involves what may be a very localized phenomenon whereby one particular group of EFL students has been shown to exhibit a well-marked tendency (over-confidence about their accuracy) in the performance of one small, but important, skill (spelling). Further field work is obviously needed to ascertain the extent to which this tendency may be found in other groups and in other skills. At this level, then, the thrust of the discussion is targetting what may be considered "area" differences in student performance where area may be defined in terms of geography or of specific skills. However in establishing a correlation between over-confidence in spelling accuracy and degree of extraversion, we have extended the focus beyond what may be localised, to something which may have more widespread implications for language teaching theory in general. Since what we have done in effect, is to progress from a "micro" question to a "macro" answer, it is obvious that much further consolidatory work is required. 


\section{NOTES}

1. These scores were obtained as follows:

Percentage mean confidence score $=$ average of the ratings for the group divided by the maximum theoretically possible rating score (i.e. number of words $\mathrm{x}$ maximum rating score, or $30 \mathrm{x} 4$ ) multiplied by 100 .

Percentage mean accuracy score $=$ average number of correctly spelled words for the group divided by the number of words, multiplied by 100 .

2. Available from the Department of Psychology, Faculty of Arts, University of Kuwait.

\section{THE AUTHOR}

Dr. Madeline Haggen completed an M.A. at Edinburgh University, Scotland; a Postgraduate Diploma in Social Study at the University of Birmingham, England; an M.A. in T.E.F.L. at The American University in Cairo; and a $\mathrm{Ph} . \mathrm{D}$. in Psycholinguistics at London University (University College).

She has university teaching experience from The American University in Cairo; the University of Algiers; The University of Mosul (Iraq); and currently, The University of Kuwait.

\section{REFERENCES}

Bebout, L. J. (1985). An error analysis of misspellings made by learners of English as a first and as a second language. Journal of Psycholinguistic Research, 14, 569-593.

Brown, H. D. (1987). Principles of language learning and teaching. (2nd ed.). Englewood Cliffs, N.J.: Prentice-Hall.

Busch, D. (1982). Introversion-extraversion and the EFL proficiency of Japanese students. Language Learning, 32, 109-132.

Cahen, L. S., Craun, M. J. \& Johnson, S. K. (1971). Spelling difficulty: A survey of the research. Review of Educational Research 41(4), 281-301.

Dulay, H., Burt, M., Krashen, S. (1982). Language two. Oxford: Oxford University Press. 
Eysenck, H. \& Eysenck, S. (1975). Eysenck personality questionnaire $(E P Q)$. London: Hodder and Stoughton.

Fitzgerald, J. A. (1932). Words misspelled most frequently by children of fourth, fifth and sixth grade levels in life outside the school. Journal of Educational Research, 26, 213-218.

Haggan, M. (1991). Spelling errors in Arabic-speaking English majors: A comparison between remedial students and fourth year students. System, 19, 45-61.

Ickenroth, J. (1975). On the elusiveness of interlanguage. Progress Report, Utrecht, December.

Kharma, N. \& Hajjaj, A. (1989). Errors in English among Arabic speakers: Analysis and remedy. London: Longman.

Kleinmann, H. H. (1977). Avoidance behaviour in adult second language acquisition. Language Learning, 27, 93-108.

Kleinmann, H. H. (1978). The strategy of avoidance in adult second language acquisition. In W. C. Ritchie, (Ed.), Second language acquisition research. Issues and implications. New York: Academic Press.

Krashen, S. (1975). A model of second language performance. Paper presented at the Linguistic Society of America, San Francisco.

Krashen, S. (1977). The monitor model for adult second language performance. In M. Burt, H. Dulay, \& M. Finocchiaro, (Eds.), Personal Viewpoints on Aspects of ESL. New York: Regents.

Krashen, S. (1978). Individual variation in the use of the monitor. In W. C. Ritchie, (Ed.), Second language acquisition research: Issues and implications. New York: Academic Press.

Naiman, N., Frohlich, M., Stern, H. H., \& Todesco, A. (1978). The good language learner. Toronto: Ontario Institute for Studies in Education.

Oller, J. W. and Ziahosseiny, S. M. (1970). The contrastive analysis hypothesis and spelling errors. Language Learning, 20, 183-189.

Perkins, K. \& Larsen-Freeman, D. (1975). The effect of formal language instruction on the order of morpheme acquisition. Language Learning, 25, 237-243.

Schachter, J. (1974). An error in error analysis. Language Learning, 24, 205-214.

Swain, M. (1975). Changes in errors: random or systematic? Paper presented at the Fourth International Congress of Applied Linguistics, Stuttgart.

Tarone, E., Frauenfelder, U. \& Selinker, L. (1975). Systematicity/ variability and stability/instability in interlanguage systems. Paper 
presented at the Sixth Annual Conference on Applied Linguistics, Ann Arbor.

Yule, G., Danico, J. \& Hoffman, P. (1987). Learners in transition.

Evidence from the interaction of accuracy and self-monitoring skill in a listening task. Language Learning, 37, 511-521.

Yule, G., Yanz, J. L., \& Tsuda, A. (1985). Investigating aspects of the language learner's confidence: an application of the theory of signal detection. Language Learning, 35, 473-488.

\section{APPENDIX A Students' Instructions Sheet}

\section{Please read the following very carefully}

1) What you are about to do is part of a research project. It has nothing to do with grades or marks. The way you answer the questions will have no effect whatsoever on your grades for this or any other course.

2) On the attached page, you will find 30 sentences or phrases where you have to supply the missing word that you think best fits in the blank space. In some cases, the first letter (and sometimes the last letter also) is written to help you guess what the word is.

3) Please try to put a word in each blank. Do not miss any out.

4) Sometimes, when we write, we want to use a word that we don't know how to spell. We write it, but we know while we are doing so that it's wrong. Other times, we guess at the spelling, but we have a strong feeling that we are not really spelling it correctly although there might be just the chance that it is right. On other occasions, we may not be $100 \%$ sure of the spelling but we write it the way we think it is spelled and, although we are still not sure we are right, we feel we are probably right. Finally, there are times when we feel sure that we have spelled the word correctly and we don't have any doubts about it.

For each of the words that you supply for the blank spaces, write after each sentence:

4 if you're sure you've spelled the word correctly

3 if you think the way you've spelled it is probably correct

2 if you think the way you've spelled it is probably wrong.

1 if you're sure you've it spelled wrongly.

5) Writing one of these numbers for each word you supply is very important. Do not forget to do it, otherwise you will spoil the research project.

6) Since this is not a test for marks, there is no point in "cheating." Please do not look at what your neighbour is writing or ask him or her for help with any of the questions.

7) Thank you for taking part. 


\section{APPENDIX B The Spelling Test}

1) In summer it is pleasant to stay in the pool.

2) She bought the blue dress although her sister said that she pr.......... the red one.

3) It was r...........y difficult to understand what he was saying.

4) That cake was delicious. I e.......... it very much.

5) Did you go to Europe last year? No, I st........... in Kuwait.

6) A day has twenty four

7) Students must work hard in order to pass th..........r exams.

8) I have known Mona for ten years. She is my best

9) .......... are fifteen students in her class.

10) I am reading a very int...........ing book about India.

11) My father's brothers are my

12) The year has twelve

13) When you feel t.........., you should go to bed.

14) Most people agree that Princess Diana is very b...........1.

15) One, .........., three.

16) We usually feel quite fresh at the $b$ of the semester.

17) The committee di the subject for an hour.

18) He teaches at the University. He is a p...........

19) A .......... must begin with a capital letter and end with a full stop.

20) The opposite of top is

21) The e.......... class was absent. Not a single student showed up.

22) My neighbour t..........s his small son to school every day.

23) In order to cure the patient, the doctor must give him the right m...........

24) At the beginning of the lecture, the speaker gave a brief ..n to his topic.

25) For some sports, you have to buy expensive clothes and e

26) Her father's refusal was a major o.......... to Ali marrying Zeinab.

27) You must stay here t.......... you have finished all your work.

28) Please pay .......... to what I am saying.

29) When there are many things to c.......... from, it is sometimes difficult to make up your mind.

30) I have many letters to write. I don't know .......... one to write first. 